\title{
Genome-wide association studies in asthma: progress and pitfalls
}

This article was published in the following Dove Press journal:

Advances in Genomics and Genetics

30 January 2015

Number of times this article has been viewed

\author{
Michael E March' \\ Patrick MA Sleiman ${ }^{1,2}$ \\ Hakon Hakonarson ${ }^{1,2}$ \\ 'Center for Applied Genomics, \\ Children's Hospital of Philadelphia \\ Research Institute, ${ }^{2}$ Department \\ of Pediatrics, Perelman School of \\ Medicine, University of Pennsylvania, \\ Philadelphia, PA, USA
}

\begin{abstract}
Genetic studies of asthma have revealed that there is considerable heritability to the phenotype. An extensive history of candidate-gene studies has identified a long list of genes associated with immune function that are potentially involved in asthma pathogenesis. However, many of the results of candidate-gene studies have failed to be replicated, leaving in question the true impact of the implicated biological pathways on asthma. With the advent of genome-wide association studies, geneticists are able to examine the association of hundreds of thousands of genetic markers with a phenotype, allowing the hypothesis-free identification of variants associated with disease. Many such studies examining asthma or related phenotypes have been published, and several themes have begun to emerge regarding the biological pathways underpinning asthma. The results of many genome-wide association studies have currently not been replicated, and the large sample sizes required for this experimental strategy invoke difficulties with sample stratification and phenotypic heterogeneity. Recently, large collaborative groups of researchers have formed consortia focused on asthma, with the goals of sharing material and data and standardizing diagnosis and experimental methods. Additionally, research has begun to focus on genetic variants that affect the response to asthma medications and on the biology that generates the heterogeneity in the asthma phenotype. As this work progresses, it will move asthma patients closer to more specific, personalized medicine.
\end{abstract}

Keywords: asthma, genetics, GWAS, pharmacogenetics, biomarkers

\section{Introduction}

Asthma is a chronic inflammatory condition of the lungs, characterized by acute episodes of breathing difficulties and hypersensitivity of the lungs to a variety of common environmental stimuli and allergens. Asthma is a complex phenotype, with wide variability in the triggers of episodes, the severity of symptoms, age of onset of symptoms, and the degree to which atopy contributes to symptoms. Worldwide estimates of asthma occurrence indicate at least 300 million individuals suffer from the condition. ${ }^{1}$ In the US, surveys from 2011 indicate that nearly 26 million Americans are asthmatic, with a rate of nearly 85 asthmatics per 1,000 individuals. ${ }^{2}$ The same report indicates that the number of child asthma patients has risen to more than 7 million, with almost 95 of 1,000 children under 18 years of age being diagnosed. Total economic impact of asthma in the US, including health care costs and lost productivity, was estimated at $\$ 56$ billion in $2007 .^{3}$ The large burden represented by asthma provides ample rationale for investigation of the causes of the condition and methods that can be used to improve treatment. The heritability of asthma has been estimated at between $36 \%$ and $77 \%{ }^{4-7}$ The study of the genetics of asthma was historically composed largely of candidate-gene

\footnotetext{
Correspondence: Patrick MA Sleiman; Hakon Hakonarson Center for Applied Genomics, Children's Hospital of Philadelphia Research Institute, 1216E Abramson Research Center, 3615 Civic Center Boulevard, Philadelphia, PA 19104-4318, USA $\mathrm{Tel}+\mathrm{I} 2674260088$

Fax + I 2674260363

Email sleimanp@email.chop.edu; hakonarson@email.chop.edu
} 
studies. However, recent advances in technology and trends in assembly of large cohorts of subjects for study have facilitated the move to genome-wide association (GWA) study, in which hundreds of thousands or millions of variants can be tested for their association with asthma or related phenotypes. GWA studies are hypothesis-independent study designs that query a significant proportion of the common variation across the genome, allowing the discovery of the contributions of novel loci. In this review, we discuss the large asthma metaanalyses performed to date, update our previous discussion on asthma GWA studies with the most recent results, and discuss how the results of these studies and the understanding of their limitations contribute to the treatment of asthma. Additionally, we discuss the efforts that have been made to translate the new discoveries in GWA studies to biological significance in asthma. Finally, we consider areas that require further investigation to improve our understanding of the asthma phenotype, and how this understanding is necessary for the progression of asthma treatment.

\section{Overview of GWA-study meta-analyses to date}

The existing GWA studies of asthma have frequently reported results generated from relatively small numbers of subjects. Most of the asthma-focused studies reported in the National Human Genome Research Institute GWA-study catalog include between 300 and 2,000 asthma subjects and comparable numbers of controls. Simulations indicate that studies of this size will be powered to find $50 \%$ of associations with common alleles (minor allele frequency between 10\% and $50 \%$ ) with an odds ratio for the susceptible allele of at least 1.3. ${ }^{8}$ Attempts to combine subject cohorts from different study sites may cause problems dealing with ethnic diversity and study-platform differences. Additionally, asthma is a phenotype with large, known, environmental factors contributing to susceptibility and severity, and geographic diversity in subject collection presents sizable difficulties in limiting the effects of these confounders in genetic studies. In an effort to increase the samples sizes used in analysis, several consortia have been formed to share access to data and biological materials. The asthma phenotype has been a focus of study for several of these consortia.

Two consortia used meta-analyses to deal with the challenges of combining data from disparate sources. Meta-analysis is the simplest technique for increasing statistical power in GWA studies by pooling samples from multiple independent investigations, and the participating members can agree on standard methods of analysis and definitions of the phenotype in order to facilitate the combined analysis. In addition to enhanced statistical power, a well-developed plan for a large meta-analysis can provide the opportunity to examine genetic factors that are common to or vary between the various contributing studies. The complexity associated with large-scale, multisite meta-analyses presents its own problems in the forms of data consistency and quality control, but the rewards are potentially large. ${ }^{9}$

The first large meta-analysis examining asthma was reported by the GABRIEL (A Multidisciplinary Study to Identify the Genetic and Environmental Causes of Asthma in the European Community) Consortium. ${ }^{10}$ This study involved multiple GWA studies in a cohort consisting of 10,365 asthma cases and 16,110 controls. The subjects in the GABRIEL study included individuals recruited from across Europe and cases and controls of European descent from Canada, Australia, and the US. The end point examined was physiciandiagnosed asthma. Analyses were performed on the entire cohort as well as five distinct subphenotypes: childhood-onset asthma, late-onset asthma, asthma developed at an unknown age, occupational asthma, and severe asthma. In addition to the asthma-outcome phenotypes, serum immunoglobulin $\mathrm{E}$ (IgE) levels were analyzed in an effort to identify overlap in the genetic factors underlying asthma and allergy.

The combined meta-analysis on all subjects identified a number of loci that were associated significantly with asthma. The association with the lowest $P$-value was found on chromosome 6 (rs9273349, $P=7 \times 10^{-14}$ ), implicating variants in the $H L A-D Q$ gene in the major histocompatibility (MHC) locus. Significant associations were found with loci on chromosome 9 (lowest $P=9 \times 10^{-10}$, found with rs1342326, near IL33), chromosome 2 (rs3771166, $P=3.4 \times 10^{-9}$, within IL18R1), chromosome 15 (rs744910, $P=3.4 \times 10^{-9}$, within $S M A D 3$ ), and chromosome 22 (rs2284033, $P=1 \times 10^{-8}$, within $I L 2 R B$ ). Although the differences were not significant, odds ratios for four of the reported loci (all except $H L A-D Q$ ) suggested a stronger association with childhood-onset asthma. The $H L A-D Q$ locus had a suggestive stronger association with asthma in adults.

Specific examination of childhood-onset asthma revealed a GWA with the well-known asthma-susceptibility locus at chromosome 17q12-21, which contains the GSDMA, $G S D M B$, and $O R M D L 3$ genes. Maximum association was found at rs2305480 $\left(P=3.4 \times 10^{-9}\right)$ within $G S D M B$. No associations were found at a genome-wide significant level with either severe or occupational asthma.

Analysis of serum IgE levels found several significant GWAs. A novel association was discovered with the MHC 
locus on chromosome 6, nearest the $H L A-D R B 1$ gene. Several loci previously described as associated with serum IgE were also found, including the FCER1A gene on chromosome 1, the IL13 gene on chromosome 5, the STAT6 gene on chromosome 12, and the IL4 and IL21R genes on chromosome 16. Strikingly, detailed comparisons of associated regions found no significant overlap between the genes associated with asthma susceptibility and those associated with serum IgE.

The results of the GABRIEL meta-analysis (Table 1) highlight the relatively small number of loci that are common across a diverse subset of asthma subjects, including childhood-onset and later-onset asthma patients. Additionally, the results suggest heterogeneity in the susceptibility to childhood- versus later-onset disease. The potentially stronger association of HLA-DQ with adultonset asthma and the strong association of the chromosome 17q12-21 region with only childhood-onset asthma provide a potential genetic explanation for the differing pathogenesis of childhood-onset and adult disease. A second meta-analysis of asthma cohorts was performed by the EVE Consortium (a collection of US-based investigators assembled to investigate asthma-susceptibility genes in ethnically diverse populations). ${ }^{11}$ The EVE meta-analysis was performed on North American cohorts of asthma cases and nonasthmatic controls. Subjects could be grouped into three general ethnically based cohorts: individuals of European descent, African Americans or Afro-Caribbeans, and Latinos. Analyses were performed on each of these subsets, as well as on the entire combined cohort. In total, this study contained 3,246 asthma cases, 3,385 controls, 1,702 asthma case-parent trios, and 355 family-based cases with 468 family-based controls.
The investigators reported and attempted replication of loci that achieved a suggestive $P$-value of $1 \times 10^{-6}$ in any of the cohorts. In the analysis of individuals of European descent, 34 single-nucleotide polymorphisms (SNPs) achieved suggestive significance; 33 of those SNPs were within the chromosome 17q12-21 locus, and the last was a potentially independent signal also on chromosome 17. Four SNPs were reported in the African-descent cohort: two SNPs within the PYHIN1 gene at chromosome 1q23, and two SNPs on chromosome 11 between the NNMT and c11orf71 genes. In the Latino cohort, 32 SNPs reached suggestive $P$-values. Twelve of these SNPs were within the 17q12-21 locus, 13 on chromosome $3 \mathrm{q} 27$ around the RTP2 gene, one SNP on chromosome $5 \mathrm{q} 33$ within GALNT10, and two SNPs on chromosome $19 \mathrm{q} 12$ between the CCNE1 and $c 19$ orf 2 genes. One SNP in the $R T P 2$ gene (rs2017908, $P=4.4 \times 10^{-9}$ ) achieved genomewide significance, and is the first asthma-susceptibility locus reported in a Latino population.

The analysis of the combined cohort revealed 15 loci of interest. Associations of genome-wide significance $\left(P<2 \times 10^{-8}\right)$ were found at the $17 \mathrm{q} 12-21$ locus (SNP with lowest $P$-value - rs $11078927 ; P=1.2 \times 10^{-14}$ ), within the ILIRLI gene (rs10173081, $P=1.4 \times 10^{-8}$ ) on chromosome 2 , and near the TSLP gene (rs1837253, $P=7.3 \times 10^{-10}$ ) on chromosome 5 . Suggestive $P$-values were obtained for a number of loci in the combined cohort, including SNPs near or within $C R C T 1$, PYHIN1, SRP9, RTP2, EPHA5, GALNT10, FBXO43, IL33, C11orf71, RASSF8, AURKB, and c19orf2. Replication was achieved with SNPs from the 17q12-21 locus and the IL1RL1, TSLP, and IL33 genes in cohorts of all three ethnicities. Replication for PYHIN1 was achieved only in a cohort of African descent.

Table I Summary of asthma meta-analysis loci referenced in this review, including chromosome location, the most significant SNP identified, and the end point of the study

\begin{tabular}{|c|c|c|c|c|}
\hline Reported gene & Locus & Top SNP & End point analyzed & Study \\
\hline \multicolumn{5}{|c|}{ Asthma meta-analyses } \\
\hline ILIRLI/ILI8RI & $2 q \mid 2.1$ & rs377II66 & Asthma in North American & Moffatt et al ${ }^{10}$ \\
\hline$H L A-D Q$ & $6 p 21.32$ & rs9273349 & populations: meta-analysis & \\
\hline IL33 & $9 p 24.1$ & rsI342326 & from the GABRIEL consortium & \\
\hline SMAD3 & $15 q 22.33$ & rs744910 & & \\
\hline IL2RB & $22 q 12.3$ & rs2284033 & & \\
\hline ORMDL3/GSDMB & $17 q 12$ & rs2305480 & & \\
\hline GSDMB & $|7 q| 2$ & rs I I078927 & Asthma in four ethnically & Torgerson et al ${ }^{11}$ \\
\hline ILIRLI & $2 q 12.1$ & rsl0I7308I & diverse North American & \\
\hline TSLP & $5 q 22.1$ & rs1837253 & populations: meta-analysis & \\
\hline IL33 & $9 p 24.1$ & rs2381416 & from the EVE consortium & \\
\hline PYHINI & Iq23.I & rsI I02000 & & \\
\hline CI lorf7I & I I q23.2 & rs|l2|4966 & & \\
\hline CRCTI & $|q 2| .3$ & rs4845783 & & \\
\hline
\end{tabular}

Abbreviation: SNP, single-nucleotide polymorphism. 
Additionally, the authors reported on attempts for replication with SNPs that had been reported by the GABRIEL Consortium and in other GWA studies. Replication was found for $H L A-D Q^{10,12}$ in all three ethnic cohorts and the combined sample. Replication was also found for the IL18RL1 and IL33 loci reported in the GABRIEL meta-analysis. ${ }^{10}$ Support was found for the SLC22A5, SMAD3, and RORA loci from the GABRIEL study only in the European-descent cohort, while evidence for the $R A D 50^{12}$ locus was observed in the Africandescent and Latino samples. Deeper investigation revealed evidence of association with two more loci: the $K L K 3$ gene on chromosome 19 (rs1061477) and SNP rs9570077 from an intergenic region on chromosome $13 .{ }^{13}$

The efforts of the EVE Consortium revealed three asthma-susceptibility loci that are shared across diverse ethnic backgrounds. These loci (17q12-21, IL1RL1, and TSLP) presumably underlie biology fundamental to the development of asthma, and their commonality between the three represented ethnic groups indicates that these may be important for future research. The reported results (Table 1) also highlight the differences between these populations, as each cohort possessed associations with loci unique to it, including the first report of a genome-wide significant association of an asthma-susceptibility locus in a Latino sample.

\section{Results of GWA studies of asthma and associated phenotypes}

The history of asthma genetics is composed largely of candidate-gene studies, in which specific genes are investigated for association with or involvement in disease. A great amount of information has been discovered in these studies, as has been reviewed elsewhere. ${ }^{14}$ However, by their nature, candidate-gene studies contain inherent bias, as the investigators are choosing in a hypothesis-driven manner which regions of the genome to investigate. GWA studies provide a framework for hypothesis-free investigation of the genetic underpinnings of a disease, avoiding the a priori biases of candidate-gene studies while also creating an opportunity for the discovery of genuinely new and completely unexpected associations.

\section{Studies on asthma susceptibility}

To date, there have been more than 30 GWA studies using asthma status (or in one case age of asthma onset) as an end point. Many of these studies report suggestive findings, having found no associations that achieved genome-wide statistical significance. Most studies reporting significant results also report successful replication within their studies.
However, there is a marked lack of replication of many results across different reports. Although it is possible that spurious results have been generated through poor study design, the likely explanation for the variability in results is simpler. Asthma is a heterogeneous phenotype, and that heterogeneity is highlighted by examination of the specific phenotypes used in various GWA studies. All asthma GWA studies begin with physician-diagnosed asthma, but the specifics vary from study-specific diagnoses to physician-reported histories of diagnoses to subject self-reported histories of diagnoses. A physician diagnosis will likely consider use of medications, but some studies report more specific requirements for frequencies, types, or strengths of medications used. Severity of asthma is frequently considered, with mild-to-moderate persistent asthma being most commonly studied. More severe phenotypes have been reported based on variable criteria, such as medications required for asthma control, measured degrees and reversibility of bronchoconstriction, or frequencies of hospitalizations or exacerbations. Pediatric cohorts have been examined, but the definition of childhood onset varies, with lower bounds from 0.5 to 5 years of age, and upper bounds from 6 to 18 years. As discussed with the metaanalyses, there is considerable geographic diversity even within ethnic groups. The reported genome-wide significant results of asthma studies are summarized in Table 2.

The ORMDL3/GSMDB locus (chromosome 17q21) is the most frequently reported and highly replicated asthmasusceptibility locus. It has been reported primarily in cohorts of European ancestry, and it has been associated with both childhood-onset disease ${ }^{15,16}$ and more general phenotypes. ${ }^{17-19}$ It is possible, as suggested in the EVE Consortium metaanalysis, ${ }^{10}$ that the signals from this locus are driven primarily by pediatric asthma.

Study of childhood-onset asthma has revealed several other loci. The PDE4D locus (5q12.1) was identified in Caucasian children with mild-to-moderate asthma with methacholine sensitivity. ${ }^{20}$ In a Mexican cohort of children with moderate or severe asthma, TLE4 (9q21.31) was identified. ${ }^{21}$ The HLA-DPA1/HLA-DPB1 (6p21.3) and SLC30A8 (8q24.11) loci were found in Japanese and East Asian asthma patients of 15 years of age or less. ${ }^{22}$ Examination of Caucasian childhood-asthma subjects who require glucocorticoids for asthma control uncovered DENND1B (1q31.3). ${ }^{16}$ Replication of this locus was found in both Caucasians and African Americans. The same variants in DENND1B were subsequently associated with elevated exhaled nitric oxide in healthy neonates who were in high-risk categories for future development of asthma and atopy. ${ }^{23}$ Analysis of the 
Table 2 Summary of asthma-susceptibility GWA-study loci referenced in this review, including chromosome location, the most significant SNP identified, and the end point of the study

\begin{tabular}{|c|c|c|c|c|}
\hline Reported gene & Locus & Top SNP & End point analyzed & Study \\
\hline \multicolumn{5}{|l|}{ Asthma-susceptibility loci } \\
\hline ORMDL3 & $\mid 7 q 12$ & rs7216389 & Childhood-onset asthma & Moffatt et al ${ }^{15}$ \\
\hline TLE4 & $9 q 21.31$ & rs2378383 & Childhood-onset asthma & Hancock et $\mathrm{al}^{21}$ \\
\hline PDE4D & $5 q \mid 2.1$ & rs 1588265 & Childhood-onset asthma & Himes et $\mathrm{al}^{20}$ \\
\hline RAD50 & $5 q 31.1$ & rs 2244012 & Severe or difficult-to- & Li et $\mathrm{al}^{12}$ \\
\hline$H L A-D R / D Q$ & $6 p 21.32$ & rs3998159 & control asthma & \\
\hline HLA-DPA I/HLA-DPBI & $6 p 21.3$ & rs987870 & Childhood-onset asthma & Noguchi et $\mathrm{a}^{22}$ \\
\hline DENNDIB & $|\mathrm{q} 3| .3$ & rs2786098 & Childhood-onset asthma & Sleiman et $\mathrm{al}^{16}$ \\
\hline IL6R & Iq21.3 & rs4I 29267 & Asthma & Ferreira et $\mathrm{al}^{28}$ \\
\hline CI lorf30/LRRC32 & $\operatorname{lIq} \mid 3.5$ & rs7। 30588 & & \\
\hline USP38-GABI & $4 q 31$ & rs7686660 & Asthma & Hirota et $\mathrm{al}^{29}$ \\
\hline TSLP/WDR36 & $5 q 22$ & rs 1837253 & & \\
\hline NOTCH4/HLA-DRA/HLA-DQA2/IKZF4 & $6 p 21.32$ & rs404860 & & \\
\hline LOC33859I & $10 p \mid 4$ & rsI0508372 & & \\
\hline IKZF4/CDK2 & $12 q 13$ & rsI70I704 & & \\
\hline ORMDL3 & $17 q 12$ & rs6503525 & Asthma & Ferreira et $\mathrm{al}^{18}$ \\
\hline clorflo & Iq44 & rs4658627 & Childhood-onset asthma & Forno et $\mathrm{al}^{24}$ \\
\hline IL5RA & $3 p 26.2$ & rs98I5663 & & \\
\hline$I L I R L I, I L I 8 R I$ & $2 q \mid 2.1$ & rs|340866| & Asthma & Ramasamy et $\mathrm{al}^{30}$ \\
\hline BTNL2, HLA-DRA & $6 p 21.32$ & rs9268516 & & \\
\hline HLA-DQAI & $6 p 21.32$ & rs9272346 & Asthma & Lasky-Su et $\mathrm{a}^{27}$ \\
\hline ORMDL3 & $17 q 12$ & rs4794820 & Severe asthma & Wan et al ${ }^{19}$ \\
\hline$I L I 8 R I, I L I R I$ & $2 q \mid 2.1$ & rs9807989 & & \\
\hline C5orf56 & $5 q 31.1$ & rsll1745587 & & \\
\hline ACOI & $9 p 21.1$ & rs10970976 & & \\
\hline ZNF665 & $19 q 13.42$ & rs16984547 & & \\
\hline NDFIPI & $5 q 31.3$ & rs6867913 & & \\
\hline IGSF3 & $|p| 3 . \mid$ & rs 17036023 & Childhood-onset & Ding et $\mathrm{a}^{25}$ \\
\hline HPSE2 & $10 q 24.2$ & rs 12570188 & severe asthma & \\
\hline PSAP & $10 q 22.1$ & rsl1000019 & & \\
\hline ATG3 & $3 q \mid 3.2$ & rs2705520 & & \\
\hline MKLNI & $7 q 32.3$ & rs7807274 & & \\
\hline$X P R I$ & Iq25.3 & rs7527074 & & \\
\hline$A B I 3 B P$ & $3 q 12.2$ & rs9823506 & & \\
\hline KLHL5 & $4 p \mid 4$ & rs35|4|484 & & \\
\hline CDHR3 & $7 q 22.3$ & rs6967330 & $\begin{array}{l}\text { Childhood-onset asthma } \\
\text { with exacerbations }\end{array}$ & Bonnelykke et $\mathrm{a}^{26}$ \\
\hline$H L A-D Q B I$ & $6 p 21.32$ & rs9273373 & Asthma and hay fever & Ferreira et al ${ }^{17}$ \\
\hline$T L R I$ & $4 p / 4$ & rs4833095 & & \\
\hline WDR36 & $5 q 22.1$ & rs|438673 & & \\
\hline ILIRLI & $2 q \mid 2.1$ & rs10197862 & & \\
\hline GSDMA & $17 q 21.1$ & rs7212938 & & \\
\hline$T S L P$ & $5 q 22.1$ & rs 1837253 & & \\
\hline IL33 & $9 p 24.1$ & rs72699186 & & \\
\hline SMAD3 & $15 q 22.33$ & rs 17294280 & & \\
\hline ZBTB।O & $8 q 21.13$ & rs7009110 & & \\
\hline CLECI6A & $16 p 13.13$ & rs62026376 & & \\
\hline
\end{tabular}

Abbreviations: GWA, genome-wide association; SNP, single-nucleotide polymorphism.

age of onset as a continuous variable in childhood-onset asthma (age 5-12 years) in children of European descent identified the clorf10 (1q44) and IL5RA (3p26.2) loci. ${ }^{24}$ Examination of severe asthma in Caucasian and African American children from multiple large, multisite collections of patients identified several unique loci, including $I G S F 3$ (1p13.1), HPSE2 (10q24.2), PSAP (10q22.1), and ATG3 (3q13.2). ${ }^{25}$ A functional polymorphism in CDHR3 (7q22.3) was found to be associated with severe asthma, as defined by the frequency and duration of asthma-related hospital stays. ${ }^{26}$ The risk variant was shown to be expressed more highly at the cell surface upon exogenous expression, suggesting this 
variant may promote cell-cell adhesion in the asthmatic lung. Binding partners for the CDHR3 protein are currently unknown, but this may represent a mechanism for increased recruitment of inflammatory cells.

Studies including adult-onset asthma, either alone or as part of a combined cohort with pediatric cases, are also abundant. The RAD50 (5q31.1) and $H L A-D R / D Q(6 \mathrm{p} 21.32)$ loci were identified in Caucasian adult subjects with severe or difficult-to-control asthma. ${ }^{12}$ The $H L A-D Q$ locus was identified again in a study combining childhood and adult subjects from multiple different recruitment sites. ${ }^{27}$ The variability in asthma phenotypes used by the different participating sites was specifically noted in the report. Analysis of a mixture of childhood and adult cases, with varying degrees of measured atopy, identified IL6R (1q21.3) and c1lorf30/ LRRC32 (11q13.5). ${ }^{28}$ Several loci, including TSLP (5q22) and NOTCH4 (6p21.32), were found in a Japanese cohort of physician-diagnosed asthma patients. ${ }^{29}$ The IL1RL1/ IL18RI locus was identified in two studies of adult cohorts of European ancestry ${ }^{19,30}$ and a study of asthma co-occurrence with hay fever. ${ }^{17}$ This latter study reported eleven loci associated with the combined asthma/hay fever phenotype, including the 17q21 locus, IL33 (9p24.1), TSLP, and CLEC16A (16p13.13).

\section{Associations with pulmonary function}

Altered lung function, and airflow obstruction in particular, is associated with both asthma and chronic obstructive pulmonary disease (COPD). Reported associations with lung function are summarized in Table 3. Except where specifically noted, the listed studies did not target specific pulmonary phenotypes, instead opting to examine all available pulmonary function test data and controlling in the analysis for the presence of pulmonary phenotypes like asthma and COPD. The CHRNA3/5 (15q24) locus surpassed GWS and was replicated in two of three independent cohorts in a study of COPD. ${ }^{31}$ The HHIP locus (4q31.22) was associated with the forced expiratory volume in 1 second $\left(\mathrm{FEV}_{1}\right) /$ forced vital capacity (FVC) ratio in three independent studies. ${ }^{32-34}$ Two of those studies reported a combined eleven novel loci associated with measures of lung function; both studies identified $A G E R$ (6p21.32) association with $\mathrm{FEV}_{1} / \mathrm{FVC}$ ratio. ${ }^{32,33}$ A series of GWA studies and a meta-analysis examining lung function in subjects of European descent replicated previously identified associations in seven loci (HHIP, FAM13A, THSD4, GSTCD, NOTCH4-AGER, RARB, and ZNF323) and found evidence for the association of four genes involved in the differentiation and function of T-helper $\left(\mathrm{T}_{\mathrm{H}}\right)-1$ cells. ${ }^{35,36}$
A study in Hutterites identified a genome-wide significant association between the THSD4-UACA-TLE3 locus on chromosome $15 \mathrm{q} 23$ and lung function. ${ }^{37} \mathrm{~A}$ large-scale effort reported association of loci on eleven chromosomes with reductions in pulmonary function, either alone or as interactions with smoking. ${ }^{38}$ A lung-function study in a pediatric cohort identified association between $\mathrm{FEV}_{1}$ and $\mathrm{FEV}_{1} / \mathrm{FVC}$ with the glycoprotein gene network in a meta-analysis of children of European and African American ancestry. ${ }^{39}$

\section{GWA studies of responses to asthma treatment}

There are comparatively few GWA studies examining the responses of asthma patients to treatments. The first reported GWA study of treatment response used a family-based screening algorithm to select statistically relevant variants potentially associated with the response of asthma patients to inhaled corticosteroids (ICS). ${ }^{40} \mathrm{~A}$ significant pharmacogenetic association was reported with rs37972 on chromosome 7, an SNP in linkage disequilibrium with GLCCI1, a glucocorticoid-induced transcript. The specific variant was associated with reduced promoter activity. These results are in keeping with results from an expression gene-array study profiling genes expressed in peripheral blood mononuclear cells from glucocorticoid-sensitive and -resistant asthma patients. ${ }^{41}$ A second GWA study, using self-reported asthmadiary entries from child subjects, identified and replicated three SNPs (rs1558726, rs2388639, and rs10044254) that associated specifically with ICS-induced improvements in self-reported asthma scores in pediatric asthma patients. ${ }^{42}$ The SNP rs10044254 lies within the FBXL7 gene, and is associated with decreased expression of the transcript.

Two GWA studies in Caucasians found GWAs with the responses of asthma patients to short-acting $\beta$-agonists (SABAs). The first study examined SABA-induced changes in lung function $\left(\mathrm{FEV}_{1}\right)$ in 1,644 Caucasian subjects. ${ }^{43}$ The investigators reported association with an SNP near the SPATS2L gene on chromosome 2. Perturbation of SPATS2L expression by small interfering ribonucleic acid-mediated knockdown in human airway smooth muscle cells resulted in enhanced expression of the $\beta_{2}$-adrenergic receptor that serves as the cellular receptor for SABAs. The second study involved SABA responses in 403 Caucasian trios, and revealed two significant hits. ${ }^{44}$ The most significant association (rs11252394) was in an intergenic region of chromosome 10 that is near the PRKCQ, IL15RA, IL2RA, and KLF6 genes. The second association was an intronic SNP (rs6988229) in the COL22A1 gene. 
Table 3 Summary of lung-function GWA-study loci referenced in this review, including chromosome location, the most significant SNP identified, and the end point of the study

\begin{tabular}{|c|c|c|c|c|}
\hline Reported gene & Locus & Top SNP & End point analyzed & Study \\
\hline \multicolumn{5}{|l|}{ Lung-function genes } \\
\hline CHRNA3/5 & $15 q 24$ & rs8034191 & COPD & Pillai et $a^{31}$ \\
\hline HHIP & $4 q 31.22$ & rs|3|47758 & $\mathrm{FEV} / \mathrm{FVC}$ & Wilk et a ${ }^{34}$ \\
\hline FAM $/ 3 A$ & $4 q 22.1$ & rs76711167 & COPD & Cho et a $\mathrm{a}^{69}$ \\
\hline HHIP & $4 q 31.22$ & rs|980057 & $\mathrm{FEV}_{1} / \mathrm{FVC}$ & Hancock et al ${ }^{32}$ \\
\hline GPRI 26 & $6 q 24.1$ & rs3817928 & $\mathrm{FEV}_{1} / \mathrm{FVC}$ & \\
\hline ADAM 19 & $5 q 33$ & rs2277027 & $\mathrm{FEV}_{1} / \mathrm{FVC}$ & \\
\hline AGER-PPT2 & $6 p 21.3$ & rs2070600 & $\mathrm{FEV} / \mathrm{FVC}$ & \\
\hline FAM I $3 A$ & $4 q 22.1$ & rs2869967 & $\mathrm{FEV}_{1} / \mathrm{FVC}$ & \\
\hline PTCHI & $9 q 22.32$ & rs16909898 & $\mathrm{FEV}_{1} / \mathrm{FVC}$ & \\
\hline PIDI & $2 q 36.3$ & rs|435867 & $\mathrm{FEV}_{1} / \mathrm{FVC}$ & \\
\hline HTR4 & $5 q 33.1$ & rsIII68048 & $\mathrm{FEV}_{1} / \mathrm{FVC}$ & \\
\hline INTSI 2-GSTCD-NPNT & $4 q 24$ & rs 17331332 & $\mathrm{FEV}_{1}$ & \\
\hline TNSI & $2 q 35$ & rs257|445 & $\mathrm{FEV}_{1}$ & Repapi et al $^{33}$ \\
\hline GSTCD & $4 q 24$ & rs 10516526 & $\mathrm{FEV}_{1}$ & \\
\hline HHIP & $4 q 31.22$ & rs 12504628 & $\mathrm{FEV}_{1} / \mathrm{FVC}$ & \\
\hline HTR4 & $5 q 33.1$ & rs3995090 & FEV $_{1}$ & \\
\hline AGER & $6 p 21.32$ & rs2070600 & $\mathrm{FEV}_{1} / \mathrm{FVC}$ & \\
\hline THSD4 & $15 q 23$ & rs 12899618 & $\mathrm{FEV}_{1} / \mathrm{FVC}$ & \\
\hline MFAP2 & $1 \mathrm{p} 36.13$ & rs2284746 & $\mathrm{FEV}_{1} / \mathrm{FVC}$ & Soler Artigas et $\mathrm{a}^{36}$ \\
\hline TGFB2 & $|q 4|$ & rs993925 & $\mathrm{FEV}_{1} / \mathrm{FVC}$ & \\
\hline HDAC4 & $2 q 37.3$ & rs $124773 \mid 4$ & $\mathrm{FEV}_{1} / \mathrm{FVC}$ & \\
\hline$R A R B$ & $3 p 24$ & rsI529672 & $\mathrm{FEV}_{1} / \mathrm{FVC}$ & \\
\hline MECOM & $3 q 26$ & rs|344555 & $\mathrm{FEV}_{1}$ & \\
\hline SPATA9 & $5 q 15$ & rsI53916 & $\mathrm{FEV}_{1} / \mathrm{FVC}$ & \\
\hline ZKSCAN3 & $6 p 22.1$ & rs6903828 & $\mathrm{FEV}_{1}$ & \\
\hline NCR3 & $6 p 21.3$ & rs2857595 & $\mathrm{FEV}_{1} / \mathrm{FVC}$ & \\
\hline$A R M C 2$ & $6 q 21$ & rs279864I & $\mathrm{FEV}_{1} / \mathrm{FVC}$ & \\
\hline ClOorfll & $10 q 22.2$ & rsl1001819 & $\mathrm{FEV}_{1}$ & \\
\hline LRPI & $12 q \mid 3.3$ & rs 11172113 & $\mathrm{FEV}_{1} / \mathrm{FVC}$ & \\
\hline CCDC38 & $12 q 23.1$ & rsI036429 & $\mathrm{FEV}_{1} / \mathrm{FVC}$ & \\
\hline MMPI5 & 16q21 & rs 12447804 & $\mathrm{FEV}_{1} / \mathrm{FVC}$ & \\
\hline CFDPI & $16 q 23.1$ & rs286553I & $\mathrm{FEV}_{1} / \mathrm{FVC}$ & \\
\hline KCNE2 & $21 q 22.1$ & rs9978I42 & $\mathrm{FEV}_{1} / \mathrm{FVC}$ & \\
\hline DNER & $2 q 36.3$ & rs759432I & Smoking-associated & Hancock et al ${ }^{38}$ \\
\hline$H L A-D Q B I, H L A-D Q A 2$ & $6 p 21.32$ & rs7764819 & declines in $\mathrm{FEV}_{1} / \mathrm{FVC}$ & \\
\hline KCNJ2, soX9 & $17 q 24.3$ & rsII654749 & & \\
\hline UPK3A & $22 q|3.3|$ & rs58667 & $\mathrm{FEV}_{1} / \mathrm{FVC}$ & Li et $\mathrm{al}^{35}$ \\
\hline$E M X 2$ & $10 q 26.11$ & rs4752066 & $\mathrm{FEV}_{1} / \mathrm{FVC}$ & \\
\hline YESI & $|8 p| 1.32$ & rs 1291183 & $\mathrm{FEV}_{1} / \mathrm{FVC}$ & \\
\hline$|L| 2 R B \mid$ & $19 p \mid 3.11$ & rs $12984 \mid 74$ & $\mathrm{FEV}_{1} / \mathrm{FVC}$ & \\
\hline THSD4, TLE3, UACA & $15 q 23$ & rs $1244 \mid 227$ & $\mathrm{FEV}_{1}$ & Yao et $\mathrm{al}^{37}$ \\
\hline $\mathrm{CDH} 2$ & $18 q \mid 2.1$ & rs879500 & FVC (Caucasians) & Ong et $\mathrm{al}^{39}$ \\
\hline MYBPCI & $12 q 23.2$ & rsl0860757 & FVC (Caucasians) & \\
\hline CTNNA3 & $10 \mathrm{q} 21.3$ & rs|47|384 & FVC (African Americans) & \\
\hline INTSI 2/GSTCD & $4 q 24$ & rsl982346 & $\mathrm{FEV}_{1}$ (meta-analysis) & \\
\hline
\end{tabular}

Abbreviations: GWA, genome-wide association; SNP, single-nucleotide polymorphism; COPD chronic obstructive pulmonary disease; FEV ${ }_{1}$, forced expiratory volume in I second; FVC, forced vital capacity.

\section{Genetics of asthma biomarkers}

The search for biomarkers of asthma continues, with the focus on finding easier and more consistent methods for the diagnosis of asthma or specific subtypes of asthma and predicting the outcome of various treatments. Historically, GWA studies searching for the genetic underpinnings of asthma biomarkers have been reported as investigations of intermediate phenotypes and quantitative traits rather than asthma itself as study end points. The results of such studies are summarized in Table 4. In a Hutterite population, an SNP in the promoter of CHI3L1 (1q32.1) was associated with both serum levels of the encoded protein and lung function. ${ }^{45}$ 
Table 4 Summary of asthma biomarker-associated GWA-study loci referenced in this review, including chromosome location, the most significant SNP identified, and the end point of the study

\begin{tabular}{|c|c|c|c|c|}
\hline Reported gene & Locus & Top SNP & End point analyzed & Study \\
\hline \multicolumn{5}{|c|}{ Biomarker associations } \\
\hline FCERIA & Iq23.2 & rs2427837 & Serum IgE levels & Weidinger et $\mathrm{a}^{46}$ \\
\hline STAT6 & $12 q 13$ & rs 12368672 & & \\
\hline RAD50 & $5 q 31.1$ & rs 2706347 & & \\
\hline CHI3LI & Iq32.I & rs4950928 & $\begin{array}{l}\text { Asthma/YKL-40 } \\
\text { serum levels }\end{array}$ & Ober et a $\left.\right|^{45}$ \\
\hline ILIRLI & $2 q \mid 2.1$ & rsl420I0I & Asthma/blood & Gudbjartsson et $\mathrm{al}^{50}$ \\
\hline IKZF2 & $5 q 31.1$ & rs 12619285 & eosinophil count & \\
\hline GATA2 & $3 q 21.3$ & rs 4857855 & & \\
\hline IL5 & $2 q \mid 2.1$ & rs4l43832 & & \\
\hline $\mathrm{SH} 2 \mathrm{~B} 3$ & $12 q 24.12$ & rs3184504 & & \\
\hline CI I orf30/LRRC32 & ||$q \mid 3.5$ & rs2155219 & Allergic rhinitis/grass & Ramasamy et a $7^{70}$ \\
\hline TMEM232/SLCA25A46 & $5 q 22.1$ & rs 17513503 & sensitization & \\
\hline HLA region & $6 p 21$ & rs7775228 & & \\
\hline FCERIA & Iq23.2 & rs225I746 & IgE levels & Granada et $\mathrm{al}^{71}$ \\
\hline $1 L / 3$ & $5 q 31.1$ & rs2054I & & \\
\hline HLA-A & 6p22.1 & rs2571391 & & \\
\hline STAT6/NAB2 & $12 q 13.3$ & rsl0595I3 & & \\
\hline DARC & Iq23.2 & rs13962 & & \\
\hline HLA-DQA2 & $6 p 21.32$ & rs285833I & & \\
\hline PTBP2 & |p2|.3 & rs321588 & Serum total & Levin et a $\mathrm{a}^{47}$ \\
\hline SUCLG2 & $3 p \mid 4.1$ & rs2363709 & IgE levels & \\
\hline MAT2B & $5 q 34$ & rs|336|473 & & \\
\hline$H L A-D Q B I$ & $6 p 21.32$ & rs9469220 & & \\
\hline$T B X 18$ & $6 q \mid 4.2$ & rs109440I7 & & \\
\hline$S O B P$ & $6 q 21$ & rs7751374 & & \\
\hline TLE4 & $9 q 21.31$ & rsI0124954 & & \\
\hline CCDC82 & ||$q 2 \mid$ & rs537526 & & \\
\hline WWP2 & 16q22.1 & rs6499255 & & \\
\hline LINC00469 & I7q25.| & rs|69777747 & & \\
\hline LYRM9 & $17 q 12$ & rs3751972 & $\mathrm{FeNO}$ & van der Valk et $\mathrm{al}^{72}$ \\
\hline NOS2 & $17 q 12$ & rs944722 & & \\
\hline GSDMB & $17 q 12$ & rs8069176 & & \\
\hline TLRI/TLR6 & $4 p \mid 4$ & rs210152I & Cat, dust-mite, and & Hinds et $\mathrm{a}^{49}$ \\
\hline WDR36/CAMK4 & $5 q 22.1$ & rs|438673 & pollen allergies & \\
\hline CI lorf30/LRRC32 & ||$q \mid 3.5$ & rs2155219 & & \\
\hline ILIRL2/ILIRLI & $2 q \mid 2.1$ & rs10189629 & & \\
\hline HLA-DQA I/HLA-DQB I & $6 p 21.32$ & rs690602I & & \\
\hline HLA-CIMICA & $6 p 21.33$ & rs9266772 & & \\
\hline PTGER4 & $5 p \mid 3.1$ & rs7720838 & & \\
\hline PLCLI & $2 q 33.1$ & rs 10497813 & & \\
\hline LPP & $3 q 28$ & rs9860547 & & \\
\hline RANBP6/IL33 & $9 p 24.1$ & rs7032572 & & \\
\hline NFATC2 & $20 q \mid 3.2$ & rs6021270 & & \\
\hline GSDMB & $17 q 12$ & rs9303280 & & \\
\hline SMAD3 & $15 q 22.33$ & rs 17228058 & & \\
\hline GATA3 & $10 p \mid 4$ & rs962993 & & \\
\hline ADADI & $4 q 27$ & rs 17388568 & & \\
\hline FOXAI/TTC6 & $|4 q 2| . \mid$ & rs1998359 & & \\
\hline TPD52/ZBTB।O & $8 q 21.13$ & rs6473223 & & \\
\hline ID2 & $2 p 25.1$ & rs10174949 & & \\
\hline CLECI6A & $16 p 13.13$ & rs7203459 & & \\
\hline IL4R/IL2IR & $16 p \mid 2.1$ & rs2107357 & & \\
\hline PEXI 4 & Ip36.22 & rs20564I7 & & \\
\hline ETSI & I lq24.3 & rsl0893845 & & \\
\hline
\end{tabular}

Abbreviations: GWA, genome-wide association; SNP, single-nucleotide polymorphism. 
The FCER1A (1q23.2) and RAD50 genes were significantly associated with serum IgE, while STAT6 (12q13) reached suggestive significance. ${ }^{46} \mathrm{IgE}$ levels were also associated with several genes with known functions in $\mathrm{T}_{\mathrm{H}}$ 2-cell skewing and allergy, including FCER1A, IL13 (5q31.1), and STAT6. Analysis of data collected within the EVE Consortium revealed ten unique regions associated with serum IgE levels, with the SNP rs 9469220 within $H L A-D Q B 1$ being most strongly associated ${ }^{47}$ This variant in the MHC locus showed association in all three ethnic groups studied in the EVE Consortium (Caucasian, African American, Latino). A recent report examined both total IgE levels and dust mite-specific IgE in a Korean population. ${ }^{48}$ Although no signals reached genome-wide significance, several different regions were suggestive for total IgE or dust mite-specific antibodies. A large study using specific self-reported allergies (cat, pollen, and dust mite) as end points identified several significant GWAs, including SNPs near TLR1/TLR6, PLCL1, IL1RL2/ $I L 1 R L 1$, and the HLA locus. ${ }^{49}$ This study is noteworthy for its use of self-reported allergic phenotypes, as well as the use of data from a private company (23andMe).Eosinophils are key mediators of allergy and asthma. Five loci reached GWA with eosinophil blood counts, ${ }^{50}$ one of which, IL1RL1, was described earlier as associated with asthma. The fraction of exhaled nitric oxide is viewed as a biomarker of eosinophilic infiltration of the lungs, and was examined as the end point of a recent GWA study. The frequently observed 17q12-21 locus was identified, and further investigation revealed an association between variants at this position and expression levels of GSDMB and ORMDL3. There was also a second signal from a nearby region on chromosome 17 , from an SNP within the LYRM9 gene. $^{50}$

\section{Functions of genes revealed by GWA studies}

Certainly, GWA studies have identified loci with very obvious connections to asthma development or pathogenesis..$^{14}$ The GABRIEL and EVE consortia reports both identified IL33 and ILIRLI as susceptibility loci. The IL-33 protein acts as a chemoattractant for $\mathrm{T}_{\mathrm{H}} 2$ cells, and is expressed by and acts on cells in lung epithelium..$^{51,52}$ The protein encoded by IL1RL1 is the receptor for IL-33, which had both a soluble and cell-membrane form. IL-33 induces the expression of $\mathrm{T}_{\mathrm{H}} 2$ cytokines in polarized $\mathrm{T}$ cells, and induces pathological tissues in IL-33-exposed mucosal tissues. The identification of both of these genes in both consortia reports highlights the importance of $\mathrm{T}_{\mathrm{H}} 2$ skewing of the immune response in asthma. Multiple studies, ${ }^{11,29}$ including the EVE Consortium report, found an association of asthma with the TSLP gene, previously reported as a GWA-study gene and risk factor for eosinophilic esophagitis. ${ }^{53}$ The TSLP protein is more highly expressed in asthmatic airways and correlates with expression of $\mathrm{T}_{\mathrm{H}} 2$ cytokines. ${ }^{54} \mathrm{TSLP}$ is produced by cells in affected tissues, and appears to be a chemokine that attracts and polarizes $\mathrm{T}_{\mathrm{H}} 2$ cells. The TSLP association with eosinophilic esophagitis ${ }^{53}$ is another condition highly dependent on $\mathrm{T}_{\mathrm{H}} 2$ cells and cytokines. ${ }^{55,56}$ Inhibition of TSLP activity by intravenous injection of a human anti-TSLP antibody for up to 3 months attenuated both early and late bronchial reactions to exposure to allergen challenge, supporting the role of this protein in allergic asthma and highlighting its potential as a therapeutic target. ${ }^{57}$ The $\mathrm{MHC}$ locus has been associated with asthma and asthma-related phenotypes in many studies, and its role in the development and activation of $\mathrm{T}$ cells makes HLA alleles key regulators of immunopathology. Other loci (such as $I L 2 R B, I L 5$, and $I L 6 R$ ) encode cytokines that contribute to the development of $\mathrm{T}_{\mathrm{H}} 2$ - or $\mathrm{T}_{\mathrm{H}} 1$-cell subsets, thereby skewing the immune response and potentially promoting pathological behavior. Genes connected to IgE antibody production or function (FCERIA) have been associated with allergic sensitization, which is satisfying given the direct role of $\mathrm{IgE}$ in such responses. Additionally, it is unsurprising to find variants in the receptors for specific drugs associated with the clinical response to those drugs.

One of the strengths of the GWA-study design is its ability to identify truly novel and unexpected associations with a phenotype, with no a priori expectations. Some loci that have been identified in association with asthma had not been previously considered in candidate-gene studies, and would not have been part of any hypotheses based on information available at the time the GWA studies were conducted. The hope was that novel loci identified would contribute to our understanding of the susceptibility and pathogenesis of asthma, and yet many loci had not been previously studied in any context, and very little information was available on the functions of the genes contained within them. This issue is perhaps highlighted best by the $17 \mathrm{q} 12-21$ locus. This region of chromosome 17 is the most highly replicated asthmasusceptibility locus to date. It has been observed in studies of every major ethnic group that has been examined, in both childhood-onset and adult asthma, and in studies focused specifically on severe asthma. The functions of the GSDMA and $G S D M B$ genes at this locus are still relatively unstudied, with only one recent report of the GSDMB protein correlating with 
invasion and metastasis in breast cancer cells. ${ }^{58}$ The product of the ORMDL3 gene also at this locus has been the subject of greater study. ORMDL3 was found to be an inducible endoplasmic reticulum protein with characteristics of proteins involved in the unfolded protein response, which appears to regulate the expression of various proteins with connection to asthma pathology. ${ }^{59} \mathrm{~A}$ recent publication from the same investigators reports that transgenic mice overexpressing ORMDL3 display characteristics of asthma patients, including increased mucus and airway remodeling. ${ }^{60}$ Additionally, the ORMDL3 protein is similar in sequence to proteins in yeast that inhibit sphingolipid synthesis. Pharmacological or genetic inhibition of sphingolipid synthesis in mice increases bronchial responsiveness to methacholine challenge. ${ }^{61}$ Generation of a transgenic or knockout mouse is obviously a large undertaking, with considerable commitment of resources and a fair amount of risk. However, it seems similar efforts will need to be undertaken for many more asthma-related loci before the functions of GWA-study loci like PYHIN1, RAD50, and $D E N N D 1 B$ will be decoded.

\section{Limitations in asthma genetic studies}

All genetic studies of asthma, whether GWA studies or other methodologies, must deal with the heterogeneity of the asthma phenotype. As discussed earlier, there is considerable evidence that childhood-onset asthma and adult disease have different genetic underpinnings. Additionally, considerable effort has been expended in the examination of allergy. However, not all asthma patients have allergies, and the pathology of atopyassociated asthma is certainly different than that of atopy-independent asthma. Furthermore, environmental factors contribute to the susceptibility or progression of asthma in many subjects, but are rarely considered in large, hypothesis-independent studies. In addition to allergens, such factors as environmental pollutants and cigarette smoke undoubtedly contribute to asthma pathogenesis. Multicenter studies include the source center as an adjustment in the analyses, but finer control for environmental influences is usually not included and would be exceptionally difficult in large, retrospective studies.

Another impact of the heterogeneity of the asthma phenotype is misdiagnosis. There are specific reports of individual subjects misdiagnosed with asthma and later shown not to be asthmatic. ${ }^{62}$ Exercise-induced breathing difficulties and bronchospasms are also frequently labeled as asthma, although individual patients may lack the inflammation common to the disease. ${ }^{63}$ Our own efforts indicate that careful consideration of diagnosis history, medication history, and response to medications must be carefully considered when trying to diagnose asthma or classify its severity, and methodical, time-consuming individual review will still reveal misclassifications in individual cases.

Finally, the drive toward larger sample sizes in GWA studies and the combination of those large samples in everexpanding meta-analyses introduces additional risks. The heterogeneity of the asthma phenotype complicates analysis. Additionally, there are several phenotypes that frequently cooccur with asthma, and the large sample sizes present in the most recent GWA studies and meta-analyses greatly increases the risk of identifying genetic variants associated with these comorbidities, particularly atopy, rather than asthma itself. Loci associated with both asthma and allergies, such as TSLP and c11orf30, may represent such cases.

\section{Potential for personalized care}

The current treatment of asthma recommended by the Global Initiative for Asthma is immediate treatment with bronchodilators to achieve relief of symptoms, followed by ICS for symptom control. The dose of ICS is increased until control is achieved, and if control cannot be achieved, prescription of oral steroids, potentially with additional anti-IgE therapies, may be required. Personalized modification of treatment regimens is imaginable, given current knowledge of the genetics of the responses to various treatments. Considerable numbers of subjects do not benefit from medications they are prescribed, and at least some of that nonresponse is attributable to genetic factors. ${ }^{64,65}$ Many of the variants described in GWA studies on treatment response have not been replicated in other reports, although issues of sample size and statistical power are likely explanations. If concerted efforts are made to expand those studies and replicate the results, genetic factors controlling treatment response could be used by physicians to inform treatment of their patients.

Although the genetics of asthma indicate multiple heterogeneous biological causes of the phenotype, treatment regimens are broadly the same from patient to patient. Variation occurs only at the specific point where each patient responds. It is likely that more individualized treatment of asthma will depend on future research on the specifics of the asthma phenotype itself. An excellent example can be found in recent descriptions of a phenotype termed " $\mathrm{T}_{\mathrm{H}} 2$-high asthma". Brushings of the airway epithelium from asthma patients and controls were assayed for gene expression by microarrays, and subjects were grouped based on the expression of a set of genes known to be induced by IL-13, a cytokine central to the generation of $\mathrm{T}_{\mathrm{H}} 2$ responses in tissues. ${ }^{66}$ The asthma patients 
could be split into two groups on this basis, with one group having expression of these genes that was indistinguishable from healthy controls and the second group having elevated expression. The group with elevated expression were considered $\mathrm{T}_{\mathrm{H}}$ 2-high asthma patients. Further investigation revealed that the response to ICS in these patients was confined almost entirely to this $\mathrm{T}_{\mathrm{H}}$ 2-high subset. Anti-IL-13 therapies are in clinical trial for asthma, and would likely target this $\mathrm{T}_{\mathrm{H}}$ 2-high subset. ${ }^{67}$ Importantly, biomarkers like the protein periostin have been found in both blood and sputum of asthma subjects that correlate well with this $\mathrm{T}_{\mathrm{H}}$ 2-high status, providing a theoretically simple technique for the identification of individuals who may benefit most from specific therapies, including ICS prescription. ${ }^{66,68}$

Opportunities abound for specific subphenotyping of asthma subjects. Molecular approaches can be taken, as with the case of the $\mathrm{T}_{\mathrm{H}}$ 2-high asthma story. Alternatively, patient histories and electronic medical records can be mined to identify cohorts with more or less aggressive disease, as was done with the identification of $C D H R 3$ as a new susceptibility locus. ${ }^{26}$ As large consortia collaborate to integrate their records, their available biological material, and their enormous stores of data, they will create opportunities for statistically powered analyses of subsets of individuals and data that were previously too small or too difficult for individual investigators to accumulate in meaningful quantities. The best hope for personalized asthma care lies in the more careful consideration of these distinct subsets. GWA studies have revealed both similarity and heterogeneity in the genetics of asthma among diverse populations. When we develop a better understanding of the biology represented by the genetic heterogeneity, we will hopefully be able to treat not just the common symptoms of asthma but the differing causative mechanisms as well.

\section{Disclosure}

The authors report no conflicts of interest in this work.

\section{References}

1. Masoli M, Fabian D, Holt S, Beasley R. The global burden of asthma: executive summary of the GINA Dissemination Committee report. Allergy. 2004;59(5):469-478.

2. American Lung Association. Data and statistics. 2012. Available from: http://www.lung.org/lung-disease/asthma/for-health-professionals-andvolunteers/\#data-and-statistics. Accessed October 16, 2014.

3. Barnett SB, Nurmagambetov TA. Costs of asthma in the United States: 2002-2007. J Allergy Clin Immunol. 2011;127(1):145-152.

4. Duffy DL, Martin NG, Battistutta D, Hopper JL, Mathews JD. Genetics of asthma and hay fever in Australian twins. Am Rev Respir Dis. 1990;142(6 Pt 1):1351-1358.

5. Harris JR, Magnus P, Samuelsen SO, Tambs K. No evidence for effects of family environment on asthma. A retrospective study of Norwegian twins. Am J Respir Crit Care Med. 1997;156(1):43-49.
6. Koppelman GH, Los H, Postma DS. Genetic and environment in asthma: the answer of twin studies. Eur Respir J. 1999;13(1):2-4.

7. Nieminen MM, Kaprio J, Koskenvuo M. A population-based study of bronchial asthma in adult twin pairs. Chest. 1991;100(1):70-75.

8. Spencer CC, Su Z, Donnelly P, Marchini J. Designing genome-wide association studies: sample size, power, imputation, and the choice of genotyping chip. PLoS Genet. 2009;5(5):e1000477.

9. Winkler TW, Day FR, Croteau-Chonka DC, et al. Quality control and conduct of genome-wide association meta-analyses. Nat Protoc. 2014;9(5):1192-1212.

10. Moffatt MF, Gut IG, Demenais F, et al. A large-scale, consortiumbased genomewide association study of asthma. $N$ Engl $J$ Med. 2010;363(13):1211-1221.

11. Torgerson DG, Ampleford EJ, Chiu GY, et al. Meta-analysis of genomewide association studies of asthma in ethnically diverse North American populations. Nat Genet. 2011;43(9):887-892.

12. Li X, Howard TD, Zheng SL, et al. Genome-wide association study of asthma identifies RAD50-IL13 and HLA-DR/DQ regions. J Allergy Clin Immunol. 2010;125(2):328-335. e11.

13. Myers RA, Himes BE, Gignoux CR, et al. Further replication studies of the EVE Consortium meta-analysis identifies 2 asthma risk loci in European Americans. J Allergy Clin Immunol. 2012;130(6):1294-1301.

14. March ME, Sleiman PM, Hakonarson H. Genetic polymorphisms and associated susceptibility to asthma. Int J Gen Med. 2013;6:253-265.

15. Moffatt MF, Kabesch M, Liang L, et al. Genetic variants regulating ORMDL3 expression contribute to the risk of childhood asthma. Nature. 2007;448(7152):470-473.

16. Sleiman PM, Flory J, Imielinski M, et al. Variants of DENND1B associated with asthma in children. $N$ Engl J Med. 2010;362(1):36-44.

17. Ferreira MA, Matheson MC, Tang CS, et al. Genome-wide association analysis identifies 11 risk variants associated with the asthma with hay fever phenotype. J Allergy Clin Immunol. 2014;133(6):1564-1571.

18. Ferreira MA, McRae AF, Medland SE, et al. Association between ORMDL3, IL1RL1 and a deletion on chromosome 17q21 with asthma risk in Australia. Eur J Hum Genet. 2011;19(4):458-464.

19. Wan YI, Shrine NR, Soler Artigas M, et al. Genome-wide association study to identify genetic determinants of severe asthma. Thorax. 2012;67(9):762-768.

20. Himes BE, Hunninghake GM, Baurley JW, et al. Genome-wide association analysis identifies PDE4D as an asthma-susceptibility gene. Am J Hum Genet. 2009;84(5):581-593.

21. Hancock DB, Romieu I, Shi M, et al. Genome-wide association study implicates chromosome $9 \mathrm{q} 21.31$ as a susceptibility locus for asthma in Mexican children. PLoS Genet. 2009;5(8):e1000623.

22. Noguchi E, Sakamoto H, Hirota T, et al. Genome-wide association study identifies HLA-DP as a susceptibility gene for pediatric asthma in Asian populations. PLoS Genet. 2011;7(7):e1002170.

23. Chawes BL, Bischoff AL, Kreiner-Møller E, Buchvald F, Hakonarson H, Bisgaard H. DENND1B gene variants associate with elevated exhaled nitric oxide in healthy high-risk neonates. Pediatr Pulmonol. Epub December 17, 2013.

24. Forno E, Lasky-Su J, Himes B, et al. Genome-wide association study of the age of onset of childhood asthma. J Allergy Clin Immunol. 2012;130(1):83-90. e4.

25. Ding L, Abebe T, Beyene J, et al. Rank-based genome-wide analysis reveals the association of ryanodine receptor-2 gene variants with childhood asthma among human populations. Human Genomics. 2013;7:16

26. Bonnelykke K, Sleiman P, Nielsen K, et al. A genome-wide association study identifies CDHR3 as a susceptibility locus for early childhood asthma with severe exacerbations. Nat Genet. 2014;46(1):51-55.

27. Lasky-Su J, Himes BE, Raby BA, et al. HLA-DQ strikes again: genome-wide association study further confirms HLA-DQ in the diagnosis of asthma among adults. Clin Exp Allergy. 2012;42(12):1724-1733.

28. Ferreira MA, Matheson MC, Duffy DL, et al. Identification of IL6R and chromosome 11q13.5 as risk loci for asthma. Lancet. 2011;378(9795):1006-1014. 
29. Hirota T, Takahashi A, Kubo M, et al. Genome-wide association study identifies three new susceptibility loci for adult asthma in the Japanese population. Nat Genet. 2011;43(9):893-896.

30. Ramasamy A, Kuokkanen M, Vedantam S, et al. Genome-wide association studies of asthma in population-based cohorts confirm known and suggested loci and identify an additional association near HLA. PloS One. 2012;7(9):e44008.

31. Pillai SG, Ge D, Zhu G, et al. A genome-wide association study in chronic obstructive pulmonary disease (COPD): identification of two major susceptibility loci. PLoS Genet. 2009;5(3):e1000421.

32. Hancock DB, Eijgelsheim M, Wilk JB, et al. Meta-analyses of genomewide association studies identify multiple loci associated with pulmonary function. Nat Genet. 2010;42(1):45-52.

33. Repapi E, Sayers I, Wain LV, et al. Genome-wide association study identifies five loci associated with lung function. Nat Genet. 2010;42(1):36-44.

34. Wilk JB, Chen TH, Gottlieb DJ, et al. A genome-wide association study of pulmonary function measures in the Framingham Heart Study. PLoS Genet. 2009;5(3):e1000429.

35. Li X, Hawkins GA, Ampleford EJ, et al. Genome-wide association study identifies TH1 pathway genes associated with lung function in asthmatic patients. J Allergy Clin Immunol. 2013;132(2):313-320. e15.

36. Soler Artigas M, Loth DW, Wain LV, et al. Genome-wide association and large-scale follow up identifies 16 new loci influencing lung function. Nat Genet. 2011;43(11):1082-1090.

37. Yao TC, Du G, Han L, et al. Genome-wide association study of lung function phenotypes in a founder population. J Allergy Clin Immunol. 2014;133(1):248-255. e1-e10.

38. Hancock DB, Artigas MS, Gharib SA, et al. Genome-wide joint metaanalysis of SNP and SNP-by-smoking interaction identifies novel loci for pulmonary function. PLoS Genet. 2012;8(12):e1003098.

39. Ong BA, Li J, McDonough JM, et al. Gene network analysis in a pediatric cohort identifies novel lung function genes. PloS One. 2013;8(9):e72899.

40. Tantisira KG, Lasky-Su J, Harada M, et al. Genomewide association between GLCCI1 and response to glucocorticoid therapy in asthma. N Engl J Med. 2011;365(13):1173-1183.

41. Hakonarson H, Bjornsdottir US, Halapi E, et al. Profiling of genes expressed in peripheral blood mononuclear cells predicts glucocorticoid sensitivity in asthma patients. Proc Natl Acad Sci U S A. 2005;102(41):14789-14794.

42. Park HW, Dahlin A, Tse S, et al. Genetic predictors associated with improvement of asthma symptoms in response to inhaled corticosteroids. J Allergy Clin Immunol. 2014;133(3):664-669. e5.

43. Himes BE, Jiang X, Hu R, et al. Genome-wide association analysis in asthma subjects identifies SPATS2L as a novel bronchodilator response gene. PLoS Genet. 2012;8(7):e1002824.

44. Duan QL, Lasky-Su J, Himes BE, et al. A genome-wide association study of bronchodilator response in asthmatics. Pharmacogenomics $J$. 2014;14(1):41-47.

45. Ober C, Tan Z, Sun Y, et al. Effect of variation in CHI3L1 on serum YKL-40 level, risk of asthma, and lung function. $N$ Engl $J$ Med. 2008;358(16):1682-1691.

46. Weidinger S, Gieger C, Rodriguez E, et al. Genome-wide scan on total serum IgE levels identifies FCER1A as novel susceptibility locus. PLoS Genet. 2008;4(8):e1000166.

47. Levin AM, Mathias RA, Huang L, et al. A meta-analysis of genomewide association studies for serum total $\mathrm{IgE}$ in diverse study populations. J Allergy Clin Immunol. 2013;131(4):1176-1184.

48. Kim JH, Cheong HS, Park JS, et al. A genome-wide association study of total serum and mite-specific IgEs in asthma patients. PloS One. 2013;8(8):e71958.

49. Hinds DA, McMahon G, Kiefer AK, et al. A genome-wide association meta-analysis of self-reported allergy identifies shared and allergyspecific susceptibility loci. Nat Genet. 2013;45(8):907-911.

50. Gudbjartsson DF, Bjornsdottir US, Halapi E, et al. Sequence variants affecting eosinophil numbers associate with asthma and myocardial infarction. Nat Genet. 2009;41(3):342-347.
51. Schmitz J, Owyang A, Oldham E, et al. IL-33, an interleukin-1-like cytokine that signals via the IL-1 receptor-related protein ST2 and induces $\mathrm{T}$ helper type 2-associated cytokines. Immunity. 2005;23(5):479-490.

52. Chackerian AA, Oldham ER, Murphy EE, Schmitz J, Pflanz S, Kastelein RA. IL-1 receptor accessory protein and ST2 comprise the IL-33 receptor complex. J Immunol. 2007;179(4):2551-2555.

53. Rothenberg ME, Spergel JM, Sherrill JD, et al. Common variants at 5 q22 associate with pediatric eosinophilic esophagitis. Nat Genet. 2010;42(4):289-291.

54. Ying S, O'Connor B, Ratoff J, et al. Thymic stromal lymphopoietin expression is increased in asthmatic airways and correlates with expression of Th2-attracting chemokines and disease severity. J Immunol. 2005;174(12):8183-8190.

55. Siracusa MC, Saenz SA, Wojno ED, et al. Thymic stromal lymphopoietin-mediated extramedullary hematopoiesis promotes allergic inflammation. Immunity. 2013;39(6):1158-1170.

56. Noti M, Wojno ED, Kim BS, et al. Thymic stromal lymphopoietinelicited basophil responses promote eosinophilic esophagitis. Nat Med. 2013;19(8):1005-1013.

57. Gauvreau GM, O'Byrne PM, Boulet LP, et al. Effects of an anti-TSLP antibody on allergen-induced asthmatic responses. $N$ Engl J Med. 2014;370(22):2102-2110.

58. Hergueta-Redondo M, Sarrio D, Molina-Crespo A, et al. Gasdermin-B promotes invasion and metastasis in breast cancer cells. PloS One. 2014;9(3):e90099.

59. Miller M, Tam AB, Cho JY, et al. ORMDL3 is an inducible lung epithelial gene regulating metalloproteases, chemokines, OAS, and ATF6. Proc Natl Acad Sci U S A. 2012;109(41):16648-16653.

60. Miller M, Rosenthal P, Beppu A, et al. ORMDL3 transgenic mice have increased airway remodeling and airway responsiveness characteristic of asthma. J Immunol. 2014;192(8):3475-3487.

61. Worgall TS, Veerappan A, Sung B, et al. Impaired sphingolipid synthesis in the respiratory tract induces airway hyperreactivity. Sci Transl Med. 2013;5(186):186ra167.

62. Park DB, Dobson JV, Losek JD. All that wheezes is not asthma: cognitive bias in pediatric emergency medical decision making. Pediatr Emerg Care. 2014;30(2):104-107.

63. Towns SJ, van Asperen PP. Diagnosis and management of asthma in adolescents. Clin Respir J. 2009;3(2):69-76.

64. Drazen JM, Silverman EK, Lee TH. Heterogeneity of therapeutic responses in asthma. Br Med Bull. 2000;56(4):1054-1070.

65. Malmstrom K, Rodriguez-Gomez G, Guerra J, et al. Oral montelukast, inhaled beclomethasone, and placebo for chronic asthma. A randomized, controlled trial. Montelukast/Beclomethasone Study Group. Ann Intern Med. 1999;130(6):487-495.

66. Woodruff PG, Modrek B, Choy DF, et al. T-helper type 2-driven inflammation defines major subphenotypes of asthma. Am J Respir Crit Care Med. 2009;180(5):388-395

67. Corren J, Lemanske RF, Hanania NA, et al. Lebrikizumab treatment in adults with asthma. $N$ Engl J Med. 2011;365(12):1088-1098.

68. Peters MC, Mekonnen ZK, Yuan S, Bhakta NR, Woodruff PG, Fahy JV. Measures of gene expression in sputum cells can identify TH2-high and TH2-low subtypes of asthma. J Allergy Clin Immunol. 2014;133(2):388-394.

69. Cho MH, Boutaoui N, Klanderman BJ, et al. Variants in FAM13A are associated with chronic obstructive pulmonary disease. Nat Genet. 2010;42(3):200-202.

70. Ramasamy A, Curjuric I, Coin LJ, et al. A genome-wide meta-analysis of genetic variants associated with allergic rhinitis and grass sensitization and their interaction with birth order. J Allergy Clin Immunol. 2011;128(5):996-1005.

71. Granada M, Wilk JB, Tuzova M, et al. A genome-wide association study of plasma total IgE concentrations in the Framingham Heart Study. J Allergy Clin Immunol. 2012;129(3):840-845. e21.

72. van der Valk RJ, Duijts L, Timpson NJ, et al. Fraction of exhaled nitric oxide values in childhood are associated with 17q11.2-q12 and 17q12q21 variants. J Allergy Clin Immunol. 2014;134(1):46-55. 


\section{Publish your work in this journal}

Advances in Genomics and Genetics is an international, peer reviewed, open access journal that focuses on new developments in characterizing the human and animal genome and specific gene expressions in health and disease. Particular emphasis will be given to those studies that elucidate genes, biomarkers and targets in the development of new or improved therapeutic interventions. The journal is characterized by the rapid reporting of reviews, original research, methodologies, technologies and analytics in this subject area. The manuscript management system is completely online and includes a very quick and fair peer-review system. Visit http://www.dovepress.com/ testimonials.php to read real quotes from published authors.

Submit your manuscript here: http://www.dovepress.com/advances-in-genomics-and-gene-expression-journal 